\title{
A comprehensive educational approach to improving NCLEX-RN pass rates
}

\author{
Angela G. Opsahl, Kathy Auberry, Beth Sharer, Carrie Shaver
}

\begin{abstract}
Background: Nurse educators strive to find the best educational methods to prepare and support students in their attempt to pass the National Council Licensure Examination for Registered Nurses (NCLEX-RN®). The purpose of this study is to describe the implementation of an online coaching program with Appreciative Advising and Emotional Intelligence education as a combined educational strategy to improve student learning outcomes.
\end{abstract}

Methods: The study was conducted at a university in the Midwestern United States. The sample consisted of students in four graduating classes $(2013, \mathrm{n}=15 ; 2014, \mathrm{n}=19 ; 2015, \mathrm{n}=18$; and 2016, $n=17$ ), who had followed supplemented program preparation in a traditional nursing baccalaureate program. Electronic surveys were disseminated to determine satisfaction with student program supports through analysis of mean overall average scoring of rates from the seven-point Likert scale. NCLEX-RN® actual pass rates were reviewed to examine the quality of online coaching toward student preparation via t-test to compare mean NCLEX-RN® pass rates before and after implementation.

Results: The students conveyed satisfaction with the new educational support additions for Appreciative Advising and Emotional Intelligence. NCLEX-RN® pass rates showed significant improvements with the combined addition of online coaching and the educational program supports for licensure exam preparation.

This is the author's manuscript of the article published in final edited form as:

Opsahl, A. G., Auberry, K., Sharer, B., \& Shaver, C. (2018). A comprehensive educational approach to improving NCLEX-RN pass rates. Nursing Forum, 53(4), 549-554. https://doi.org/10.1111/nuf.12285 
Conclusion: The findings suggest that nursing schools that include student support with an online coaching program can result in positive trends related to NCLEX-RN® pass rates.

Keywords: appreciative advising, coaching, emotional intelligence, National Council Licensure Examination for Registered Nurses, nursing education

A Comprehensive Educational Approach to Improving NCLEX-RN Pass Rates

\section{Introduction}

Baccalaureate nursing schools across the country seek to acquire commission accreditation that ensures the quality and integrity of programs to produce competent nurse graduates (Commission on Collegiate Nursing Education, 2016). These accrediting bodies require schools to demonstrate comprehensive plans of assessment and evaluation that include benchmarks for national licensure exam success to maintain program approval status. Prelicensure nursing program faculty are charged with designing and delivering curricula which enable graduates to be successful on the NCLEX-RN® and comply with their state and national regulatory agencies. Nurse educators strive to find the best educational methods for the preparation of students attempting to pass the National Council Licensure Examination for Registered Nurses (NCLEX-RN®). The current benchmark for the NCLEX-RN® examination shows an average first-time pass rate of $85.26 \%$ over the most recent three years (National Council of State Boards of Nursing, 2016). The overall focus for schools of nursing across the country surrounds the need to educate competent graduates who will successfully achieve the NCLEX-RN® examination, attain state licensure, and safely serve the public (Billings \& Halstead, 2012). The purpose of this article is to describe the implementation of an online 
coaching program with additional student academic supports as a strategy to improve studentlearning outcomes as part of an overall comprehensive nursing program educational approach.

\section{Background}

Nurse administrators and faculty all share similar goals and challenges related to educating members of our profession. With the ever-changing landscape of the healthcare industry, the NCLEX-RN® examination remains the consistent method of testing to verify the minimum required knowledge by students, to convey safe nursing practice, and serve as a prominent indicator of program quality. The National Council of State Boards of Nursing (NCSBN () works to ensure testing applicants have the necessary knowledge to meet standards for public protection requirements, including safety competencies as an entry-level registered nurse (National Council of State Boards of Nursing, 2016). The study site program is a growing, dynamic campus located in the Midwest and offers a traditional Bachelor of Science in Nursing (BSN), RN to BSN, and BSN Second Degree Accelerated tracks with hundreds of applicants each year. Schools of nursing work to screen student applicants for rigorous program coursework, which prepares students for the NCLEX-RN® through supportive curriculum, and services that include educational innovations (Cole \& Adams, 2014). First-time NCLEX-RN® pass rates convey program quality and are utilized as a measure by national accrediting bodies (Claussen, 2012). The accomplishment in passing the NCLEX-RN® board examination requires the valuable assets of skills acquisition, knowledge achievement, and critical thinking application by students (Romeo, 2013, \& Simon, McGinniss, \& Krauss, 2013).

Evidence-based practice approaches are essential in determining effective educational strategies for the nursing profession. The results of infusing these practical teaching approaches 
will provide stronger evidence for an innovative interventional strategy that improves NCLEX$R N \circledast$ pass rates. The combination of formative and summative assessment tools with a comprehensive predictor exam have demonstrated improvements in student efficacy (Phelan, 2014). Increased utilization of this approach has caught on in nursing programs throughout the country. The online coaching programs with supplemental learning exercises supply an increased complexity throughout the nursing curriculum, which culminates in a comprehensive examination to predict performance with NCLEX-RN® examination on the student's first attempt (Killingsworth, Kimble, \& Sudia, 2015). The now popular end-of-program online nursing coaching systems require frequent interactions between the Master of Science in Nursing (MSN) prepared nurse coach and the student culminating in the comprehensive predictor exam to gauge student success with the national board exam for licensure and program completion. To efficiently teach our millennial population of students, faculty must be willing to adapt their teaching strategies with program supports to engage and facilitate student learning toward NCLEX-RN® success (Lown \& Hawkins, 2017; Reilly, 2012).

In addition to the online coaching format to assist students with NCLEX-RN® preparation, the academic program support of Appreciative Advising was introduced to students throughout the program. Academic Advising is considered an integral component of student retention and success (DeSousa, 2005). The study site-nursing program utilized Appreciative Advising as the theoretical framework/design in developing and maintaining relationships with students. Appreciative Advising is an entirely student-centered approach with the intentional collaborative practice to support students in optimizing their educational experiences and achieving their full potential (Bloom, Hutson, Ye, and Konkle, 2013). Within this framework, advisors work with the student to highlight their qualities and build a specific academic 
achievement plan. This design utilizes open-ended questioning with positive reinforcement to develop the crucial relationship between student and advisor to help students achieve their academic goals. The study site nursing advisors launched Appreciative Advising with all students within the program from admission to graduation, with special emphasis on the sophomore students new to the school of nursing.

The school also decided to introduce Emotional Intelligence (EI) as academic support to students as they entered the program. EI applies to an individual's ability to perceive emotions in self and others, to understand emotions and psychological meanings, and to self-regulate emotions by encouraging emotional and intellectual growth (Stein \& Book, 2011). Schools of nursing should work to develop students' social awareness and social skills as this will influence the care students deliver in their clinical education and throughout their career (Fitzpatrick, 2016). Studies have indicated a strong correlation between professional competence and emotional intelligence (Beauvais, Stewart, DeNisco, \& Beauvais, 2014; Por et al., 2011). A recent study found a strong correlation between EI development in nursese and their carieng behaviors for patients (Nightingale, Spiby, Sheen, \& Slade, 2018). The nursing students at the study site received professional development education on EI starting in the prerequisite coursework from the advisors. Nursing program advisors at the study site were certified as emotional quotient intelligence (EQi) coaches. EI was integrated into the program's first-year seminar and taught by the academic advisors using Appreciative Instruction, which is an offshoot of Appreciative Advising. Students created their own EI improvement plan as part of this coursework. The individual EI improvement plan was further developed and utilized for remediation with those students exhibiting professional behavior issues. This emotional/behavioral training was implemented early in the program with coursework from the 
time the students entered the study site program and coincided with the addition of the online coaching efforts.

\section{Methods}

After the 2013 pass rate scores, the study program faculty decided that all senior BSN students in the nursing program must receive access to a 12-week, personalized, online support with an MSN prepared coach, who would work weekly with each student on focus areas related to the NCLEX-RN® exam. The authors' university institutional review board approved the study for the program campus at a university in the Midwestern United States. The convenience sample comprised all students who completed/graduated the prelicensure baccalaureate program at the university and took the NCLEX-RN® from May 2013 to August 2016. The nursing program admitted a cohort of approximately 20 students annually, with class sizes varying due to last-minute applicant withdrawals and student attrition. The initial practice change consisted of the implementation of predictor examination and online coaching at the end of the program as a supplemental educational strategy toward NCLEX-RN® preparation as part of our comprehensive strategy. With the nursing program already utilizing Assessment Technologies Institute (ATI) online nursing study tools, the program faculty reviewed the literature for support of this new program to aid in student preparation for board licensure. A review of the literature found a positive correlation between completion of the ATI RN comprehensive predictor assessment with necessary student coach remediation and improved first-time pass rates on the NCLEX-RN (Winters, 2013). The nursing faculty chose to employ decided the Virtual Assessment Technologies Institute (VATI) program as a combination of an RN comprehensive predictor assessment tool and personalized coaching support content for the NCLEX-RN® exam to help support the students. This mode of NCLEX-RN® licensure preparation relies on the one- 
to-one relationship between the student and an assigned personal coach to assist the student through individual content mastery assessments tied to the licensure exam (Shoemaker, Chavez, Keane, Butz, \& Yowler, 2017). On completing the 12-week online end-of-program support content with a coach, the students received an approval to test from their online coach when the student had passed at a superior mark within each of the focus areas related to the NCLEX-RN® examination. The online coach then encouraged the student to test with the state for the NCLEX-RN® exam within three weeks of receiving the coach's approval to test. Infusing necessary student educational supports earlier in the nursing program was then actively pursued by the program faculty and staff in the spring of 2014. The online end-of-program coaching support was further enhanced through the overall program decision to provide the addition of Appreciative Advising and Emotional Intelligence supports for all nursing students as a comprehensive approach.

The entire nursing program faculty and staff approved the proposal to add the online coaching program to incorporate a content-specific NCLEX-RN® review. This supplemental educational strategy was additionally supported by our advisory council comprised of clinical partners and employers in the region. All stakeholders were supportive of the implementation following the 2013 graduating class with yearly analysis of the progress of each subsequent graduating class. To measure the effectiveness of the online coaching program, NCLEX-RN® mean first-time pass rates were utilized from all available students in the traditional baccalaureate program from 2013-2016. A t-test was used to compare mean NCLEX-RN® pass rates before and after implementing the online coaching program. Student satisfaction ratings of the program academic supports were collected through an online Likert scale survey. Program academic supports were measured through the online Qualtrics ${ }^{\circledR}$ platform, survey software with 
analytics, questionnaire comprised of twelve questions including open comment area for the student response (see Figure 1). The Likert scale satisfaction questions centered on feedback about providing appropriate information, setting academic career goals, imparting encouragement, and accommodating needs.

\section{Results}

Findings indicated a marked increase in pass rates when comparing the first-time NCLEX-RN® pass rates before the implementation of the new program approach with the added online coaching and student academic supports (see Table 1). The mean student NCLEX-RN® first time pass rates for the three years following implementation of the online coaching program were significantly higher $(\mathrm{P}<0.01)$ than the mean NCLEX-RN® pass rate for the time frame before utilizing this educational strategy (see Table 2). Program student overall NCLEX-RN® pass rates were 100\% after the initial implementation of the new program approach in 2014 . Most recently, the ATI RN comprehensive predictor assessment has been found to closely correspond to the testing material on the NCLEX-RN® test plan (Liu \& Mills, 2017). The student program academic support satisfaction rates, collected through the Qualtrics ${ }^{\circledR}$ platform, were measured with a seven-point Likert scale. Appreciative Advising support outcome scores were positive at less than 5.65 , with the mean overall average score of 6.4 for the past 2 years.

\section{Conclusion}

The findings suggest that a nursing program that includes educational strategies of a comprehensive predictor assessment with online coaching and supplemental academic support components can result in positive trends related to NCLEX-RN@ first time pass rates for students. The process has provided a significant opportunity for the nursing program faculty and 
staff to come together and determine those areas of need related to student success. This study supports the utilization of enhanced advising practices of Appreciative Advising and Emotional Intelligence in nursing. The continued sharing of knowledge and the reinforcement of the program goals with the faculty, staff, students, and our community of interest have resulted in sustained positive student outcomes. More research is recommended for further investigation of this multifaceted approach to support undergraduate nursing programs.

\section{References}

Beauvais, A. M., Stewart, J. G., DeNisco, S., \& Beauvais, J. E. (2014). Factors related to academic success among nursing students: A descriptive correlational research study. Nurse Education Today, 34(6), 918-923.

Billings, D. M., \& Halstead, J. A. (2012). Teaching in nursing: A guide for faculty (4th ed.). St. Louis, Mo.: Elsevier/Saunders.

Bloom, J. L., Hutson, B. L., He, Y., \& Konkle, E. (2013). Appreciative education. New Directions for Student Services, 143, 5-18.

Claussen, T. (2012). NCLEX-RN® pass rates. ASBN Update, 16(5), 16-17.

Cole, L. G., \& Adams, M. H. (2014). A multifaceted progression approach to enhancing student success. Nurse Educator, 39(6), 285-289.

Commission on College Nursing Education. (2016). Standards for accreditation of baccalaureate and graduate nursing programs. Retrieved from http://www.aacnnursing.org/CCNE-Accreditation/Resource-Documents/Program-

\section{$\underline{\text { Resources }}$}


DeSousa, D. J. (2005). What advisors can do. (Occasional Paper No. 11). National Survey of Student Engagement. Retrieved March 23, 2017 from http://nsse.indiana.edu/institute/documents/briefs/DEEP $\% 20$ Practice $\% 20 \mathrm{Brief} \% 2011 \% 2$ 0What\%20Advisors\%20Can\%20Do.pdf.

Fitzpatrick, J. J. (2016). Helping nursing students develop and expand their emotional intelligence. Nursing Education Perspectives, 37(3), 124.

Killingsworth, E., Kimble, L. P., \& Sudia, T. (2015). What goes into a decision? How nursing faculty decide which best practices to use for classroom testing. Nursing Education Perspectives, 36(4): 220-225.

Liu, X., \& Mills, C. (2017). Assessing the construct congruence of the RN comprehensive predictor and NCLEX-RN test plan. J Nurs Educ, 56(7), 412-419.

Lown, S. G., \& Hawkins, L. A. (2017). Learning style as a predictor of first-time NCLEX-RN success: implications for nurse educators. Nurse Educator, 42(4), 181-185.

National Council of State Boards of Nursing. (2016). NCLEX-RN exam statistics and publications. Retrieved from https://www.ncsbn.org/exam-statistics-andpublications.htm

National League for Nursing Commission for Nursing Education Accreditation (2016). NLN CNEA accreditation standards for nursing education programs. Retrieved from http://www.nln.org/docs/default-source/accreditation-services/cnea-standards-finalfebruary-201613f2bf5c78366c709642ff00005f0421.pdf?sfvrsn=4

Nightingale, S., Spiby, H., Sheen, K., \& Slade, P. (2018). The impact of emotional intelligence 
in health care professionals on caring behaviour towards patients in clinical and longterm care settings: findings from an integrative review. Int J Nurs Stud. 80, 106-117.

O'Lynn, C. (2017). Rethinking indicators of academic quality in nursing programs. Journal of Nursing Education, 56(4), 195-196.

Phelan, J. (2014). Lippincott for life: HESI/ATI research summary. National Center for Research on Evaluation, Standards and Student Testing. Los Angeles, CA: University of California-Los Angeles Press.

Por, J., Barriball, L., Fitzpatrick, J., \& Roberts, J. (2011). Emotional intelligence: Its relationship to stress, coping, well-being and professional performance in nursing students. Nurse Education Today, 31(8), 855-860.

Reilly, P. (2012). Understanding and teaching generation Y. English Teaching Forum, 50, 2-11.

Romeo, E. M. (2013). The predictive ability of critical thinking, nursing GPA, and SAT: Scores on first-time NCLEX-RN® performance. Nursing Education Perspectives, 34(4), 248253.

Serembus, J. (2016). Improving NCLEX first-time pass rates: A comprehensive program approach. Journal of Nursing Regulation, Vol. 6, Issue 4, 38-44.

Shoemaker, J. R., Chavez, R. A., Keane, P., Butz, S., \& Yowler, S. K. (2017). Effective utilization of computerized curricular assistive tools in improving NCLEX-RN pass rates for a baccalaureate nursing program. CIN: Computers, Informatics, Nursing, 35(4), 194-200. 
Simon, E. B., McGinniss, S. P., \& Krauss, B. J. (2013). Predictor variables for NCLEX-RN® readiness exam performance. Nursing Education Perspectives, 34(1), 18-24.

Stein, S. J., \& Book, H. E. (2011). The EQ edge: Emotional intelligence and your success. Mississauga, Ontario: Jossey-Bass.

Taylor, H., Loftin, C., \& Reyes, H. (2014). First-time NCLEX-RN pass rate: Measure of program quality or something else? Journal of Nursing Education, 53(6), 336-341.

Winters, A. S. (2013). The efficacy of ATI predictive testing and remediation on National Certification and Licensure Examination-Registered Nurse pass rates. ProQuest LLC. 12-17. 